\title{
Government policy under price uncertainty: a source of volatility in illegal immigration
}

Article

Accepted Version

Guzman, M. G., Haslag, J. H. and Orrenius, P. M. (2015) Government policy under price uncertainty: a source of volatility in illegal immigration. Canadian Journal of Economics, 48 (3). pp. 940-962. ISSN 0008-4085 doi: https://doi.org/10.1111/caje.12164 Available at https://centaur.reading.ac.uk/34222/

It is advisable to refer to the publisher's version if you intend to cite from the work. See Guidance on citing.

To link to this article DOI: http://dx.doi.org/10.1111/caje.12164

Publisher: Wiley

All outputs in CentAUR are protected by Intellectual Property Rights law, including copyright law. Copyright and IPR is retained by the creators or other copyright holders. Terms and conditions for use of this material are defined in the End User Agreement.

www.reading.ac.uk/centaur 
Central Archive at the University of Reading

Reading's research outputs online 


\section{Government Policy under Price Uncertainty: A Source of}

$$
\text { Volatility in Illegal Immigration }{ }^{1}
$$

\author{
Mark G. Guzman ${ }^{2}$ \\ Department of Economics \\ University of Reading
}

\author{
Joseph H. Haslag \\ Department of Economics \\ University of Missouri
}

Pia M. Orrenius

Research Department

Federal Reserve Bank of Dallas

March 29, 2013

\footnotetext{
${ }^{1}$ We would like to thank Scott Dressler for his diligent research assistance and Jim Peck, Van Pham, Erwan Quintin, and anonymous referees for their helpful comments. The views expressed are those of the authors and do not represent the views of the Federal Reserve Bank of Dallas or the Federal Reserve System. All errors and omissions are the authors alone.

${ }^{2}$ Correspondent Author: University of Reading, Department of Economics, PO Box 217, Whiteknights, Reading, RG6 6AW, UK. E-mail: m.g.guzman@reading.ac.uk
} 


\begin{abstract}
In this paper we provide an alternative explanation for why illegal immigration can exhibit substantial fluctuation. We develop a model economy in which migrants make decisions in the face of uncertain border enforcement and lump-sum transfers from the host country. The uncertainty is extrinsic in nature, a sunspot, and arises as a result of ambiguity regarding the commodity price of money. Migrants are restricted from participating in state-contingent insurance markets in the host country, whereas host country natives are not. Volatility in migration flows stems from two distinct sources: the tension between transfers inducing migration and enforcement discouraging it and secondly the existence of a sunspot. Finally, we examine the impact of a change in tax/transfer policies by the government on migration.
\end{abstract}

JEL: D51, E62, F22 


\section{Introduction}

Researchers have offered competing theories to account for fluctuations in illegal immigration. Hanson and Spilimbergo (1999) and Borger (2009), for example, take the logical first step, demonstrating that wage differentials play an important role in accounting for illegal immigrant flows in the U.S.-Mexico case. In addition, Hanson and McIntosh (2010) study how differences in the relative size of the labor force in the origin and destination countries affect the volume of unauthorized migration. Hanson and Spilimbergo (2001) also present evidence that is consistent with political economy motives governing border enforcement. When industries that rely more heavily on illegal workers experience sectoral shocks, then enforcement wanes. Hence, conditions in these industries help to account for fluctuations in illegal immigration.

Another literature has focused more on existing institutional features that seek to reduce frictions that hinder unauthorized flows. In Guzman et al. (2008), the authors present a model in which smugglers are a means for circumventing border enforcement. Guzman et al. (2004) and Taylor (1986) study how migrant networks and border enforcement affect migration costs and therefore, illegal immigration. Stark and Wang (2002) and Carrington et al. (1996) focus explicitly on the dynamic effects of networks, developing models in which migration can intensify even as wage gaps shrink due to cumulative network formation. Finally, more recent papers have examined issues related to business cycles and their impact on migration. Borger (2009) focuses on the impact of the business cycle on migration in an empirical model whereas Mandelman and Zlate (2012) develop a dynamic stochastic general equilibrium (DSGE) model to understand the interrelationships between the wider economy, immigration and remittances.

In this paper, we consider the role of extrinsic uncertainty as a means to account for illegal immigrant flows. The rationale for considering such an approach is grounded in real-world forms of uncertainty that enter into policy discussions and hence, individual decision making. For example, the programs that consider granting unauthorized migrants a path to permanent residency, often labelled as amnesty programs, alter people's expectations regarding the returns to migration. Consequently, in a general equilibrium framework we examine how extrinsic price uncertainty (sunspots), via its impact on the values of taxes and thus the value of host-country government transfers to immigrants, can affect immigration. Our paper follows in the vein of Guzman et al. (2008) and Guzman et al. (2004) and, to a lesser extent, the theoretical literature 
which focuses on network externalities. ${ }^{1}$ We specify a two-period overlapping generations model. As such, our model cannot be readily applied to studying dynamics at business-cyle frequencies such as the paper by Mandelman and Zlate (2012). Instead, we focus on longer term fluctuations. ${ }^{2}$ The trade-off for focusing on the longer run is that we are able to examine a richer set of dynamic equilibria. While DSGE models are limited to exploring the local dynamics around a stable steady state (where both the existence of a unique steady state and its stability must be assumed), we will develop a model with multiple steady states and be able to study global dynamics. As we will show, the existence of multiple steady states provides an explanation for fluctuations in migration (independent of sunspots); one of the two chief contributions of this paper.

Our results show that illegal immigration fluctuates for two distinct reasons. First, there is no coordinating mechanism when multiple equilibria exist. Second, there is extrinsic price uncertainty (sunspots) that arise when either there is a unique equilibrium or when multiple equilibria exist. As with the network externality literature, we emphasize the role of non-wage factors in accounting for fluctuations, but unlike this literature we emphasize economic variables that impact both the marginal costs and benefits of migration. ${ }^{3}$ Specifically, we focus on the role of government transfers, border enforcement, and human smugglers as the primary forces affecting migration fluctuations. Governments, like in the United States, have used these policy instruments (border enforcement and restricting transfers to immigrants) to stem rising illegal immigration in recent years. ${ }^{4}$ We demonstrate that multiple equilibria can arise as a result of the tensions existing between enforcement and transfers (as factors discouraging, encouraging migration respectively) and fluctuations can occur as there exists no mechanism for coordinating on equilibria over time. In addition, we introduce extrinsic uncertainty, sunspots, regarding the real value of nominal taxes and transfers. As a result of the sunspot, not only do the values of government transfers and taxes vary, but also the resources

\footnotetext{
${ }^{1}$ Our paper differs from the network externality literature in that the network literature focuses chiefly on explaining increases to migration, and does not easily lend itself to account for the volatility observed in actual migration patterns - as it cannot account for falling, or even stable, migration flows.

${ }^{2}$ For example, amnesties (in most countries) are events which occur infrequently. Hence, our two-period model, where periods correspond to a generation in the real world, would be better suited to explaining these types of events. See Machado (2012) and Karlson and Katz (2010) for examples of two-period models which explore the interrelationships between amnesties, border enforcement and welfare.

${ }^{3}$ As will become explicit later on, we will make a distinction between wages (where we will assume a constant wage gap) and all other benefits from migrating.

${ }^{4}$ The Personality Responsibility and Work Opportunity Reconciliation Act of 1996 is an example of changes in government transfer programs that may influence migration flows. Angelucci (2012), Gathmann (2008), and Amuedo-Dorantes and Bansak (2007) are among empirical papers that demonstrate the deterrent impact of border enforcement.
} 
devoted to border enforcement. Sunspots have been used to study endogenous fluctuations in other literatures: most notably in the business cycle fluctuations literature. ${ }^{5}$ Insofar as endogenous fluctuations can explain observed volatility in output, they may also represent a partial explanation for observed volatility in illegal immigration.

In this economy, a person is born in one of two countries. Since the analysis concerns only one-way migration, we designate one country the home country (where potential migrants are born) and the other is called the host country (to which migrants move). In the host-country, nature separates newborns into either the skilled or unskilled group. Both sets of individuals supply labor, earn wages, pay taxes, and consume. The nominal value of taxes is known, while the goods value is not — due to uncertainty regarding the price level. ${ }^{6}$ In the host country, there is a market for state-contingent securities. We assume limited participation in the state-contingent security market; that is, only people born in the host country can trade in the state-contingent security market while home-country people are excluded. Host-country people use the state-contingent security market to partially insure against price level uncertainty, and hence consumption volatility. Tax revenues are distributed between two government activities: border enforcement and transfers to migrant workers. ${ }^{7}$ Since commodity prices are the only random variable in this economy, the uncertainty in our model is extrinsic in nature. As has been shown in previous literature, participation can matter for equilibria allocations under extrinsic uncertainty. ${ }^{8}$

When born, we have two types of home-country young people. One type are labelled workers and the other type are labelled smugglers. In addition, each young person is endowed with one unit of time. For workers born in the home country, their time is allocated to working in the home country, with any remaining time allocated between crossing the border (evading enforcement) and working in the host country. We

\footnotetext{
${ }^{5}$ See, for instance, Azariadas and Guesnerie (1986), Woodford (1987), Farmer and Guo (1994), Farmer and Woodford (1997), and Benhabib and Kazuo (1998) for examples of model economies in which sunspots are offered as a possible explanation for the volatility observed in real GDP at business cycle frequencies.

${ }^{6}$ Our analysis builds on the methods developed in Bhattacharya et al. (1998) and Keister (1998). These papers derive conditions under which stationary sunspot equilibria are not mere randomizations over certainty equilibria, and thus, sunspots matter in a material sense. One difference in our model is that there is a "natural" restriction in which individuals not born in the host country do not have access to the state-contingent insurance markets available to host-country workers, although these restricted individuals are still assumed to be born after the state of nature is revealed.

${ }^{7}$ We will abstract from the fact that taxes are used for a variety of purposes in the real world. Instead we focus on tax revenue as it relates to its uses regarding illegal immigration (transfers and border enforcement).

${ }^{8}$ For a more complete discussion of extrinsic uncertainty, see Cass and Shell (1983) and Balasko (1983). Also related, Balasko and Shell (1986) study an overlapping-generations model in which lump-sum taxes and transfers are present. See Cass and Shell (1983), Woodford (1986), Cass (1992), Balasko and Shell (1993) for a thorough development of the role of limited participation on fluctuations in stationary sunspot equilibria.
} 
assume all home-country workers are unskilled. Migrant workers receive wage income and benefits from the host-country transfer program (e.g., education and health services). ${ }^{9}$ Smugglers are endowed with some knowledge of border enforcement techniques and allocate their labor time between acquiring additional information regarding border patrols and arranging for border crossings. Migrants who use the services of smugglers spend less time crossing the border and more time working in the host country relative to migrants who do not use smugglers.

Our results are easily summarized as follows. First, we classify two distinct sources of potential volatility which help explain fluctuations in migration that are neither wage driven nor dependent on networks. ${ }^{10}$ Specifically, we derive conditions under which there exist multiple (two), non-sunspot equilibria in this economy. Multiple equilibria derive from the interplay between transfers received from migrating (migration benefits) and the resulting impact these have on border crossing frictions (migration costs). These frictions, in turn, depend on the level of border enforcement and the smuggling industry. Thus, by explicitly, and more realistically, modeling the frictions affecting both marginal costs and benefits, we derive combinations of migrant flows, transfers and enforcement levels at which the utility maximizing migrant is indifferent. However, there is no mechanism for coordinating on a particular equilibria, and over time, nothing prevents the economy from switching between equilibria, for a given realization of the sunspot. Hence volatility in migration patterns may result from the interactions between enforcement and transfers. Second, we show that sunspot equilibria exist in this economy and that they are not mere randomizations over certainty equilibria. As a result, even when there exists a unique equilibrium, the two states of nature associated with the sunspot offers another source of volatility to the migration pattern. Third, we consider the effects that a change in transfer payments (or conversely taxes) would have on equilibrium outcomes. As expected, the exact impact of policy changes is highly dependent on which equilibrium and which state of nature prevails.

The remainder of the paper is arranged as follows. The basic model is outlined in Section 2. Section 3 defines sunspot equilibria and shows existence of pure sunspot equilibria while Section 4 describes the equilibrium values for the level of migration and quantity of smugglers services. We obtain the comparative

\footnotetext{
${ }^{9}$ Since our focus is on the determinants of migration, we will abstract from (ignore) general transfer programs aimed at host country natives.

${ }^{10}$ As mentioned previously, we are not contending that wages and networks provide no explanation for fluctuations in migration. Instead we are focusing on other aspects of the migration decision which can lead to volatility.
} 
static results in Section 5. Section 6 offers a brief summary and conclusions.

\section{The Model}

There is an infinite number of discrete time periods, with time indexed by $t=0,1,2, \ldots$ We consider a world consisting of two countries: a home country, from which individuals may choose to emigrate, and a host country, to which individuals illegally immigrate. No one born in the host country leaves. At each date $t \geq 0$, there is a continuum of agents of measure one born in each country, living for two periods. Each agent born is endowed with one unit of time when young and nothing when old. There is a single, perishable consumption good. Each agent values old-age consumption.

We also introduce extrinsic uncertainty (i.e., sunspots) into the model economy. It is assumed that all taxes and transfers are denominated in nominal units, which for simplicity we will refer to as dollars. The goods price of these dollars, $\rho$, is assumed to be sunspot dependent. ${ }^{11}$ We assume that there are two possible states of nature: $s \in\{\alpha, \beta\}$. Thus the value of a unit of taxes will either be $\rho(\alpha)$ or $\rho(\beta)$ depending on which state occurs. Finally, we assume that the likelihood of state $\alpha(\beta)$ occurring is given by the probability $\pi(1-\pi)$ respectively.

\subsection{Host Country}

Agents born in the host country are distinguished by their skill level. For simplicity, we assume there are two types of individuals: skilled and unskilled. Let $\varepsilon$ represent the measure of skilled workers born in the host country at each date $t \geq 0$. An individual's skill level is common knowledge and an indication of their marginal productivity. At each date $t \geq 1$, the host-country production technology transforms labor into the consumption good. Each host-country worker is paid their marginal product.

All host-country workers, regardless of skill level, have access to state-contingent markets for trading securities prior to the realization of the state, $s$ and spot markets for trading goods after the realization of state $s$. The former allows all host country workers the ability to (partially) insure themselves against the uncertainty regarding the future state of nature.

\footnotetext{
${ }^{11}$ We follow Shell (1977), Cass and Shell (1983), Bhattacharya et al. (1998), Keister (1998), etc. in having the sunspot dependent variable be the price of money.
} 


\subsubsection{Skilled Worker's Problem}

Skilled workers inelastically supply their one unit of labor when young. They earn a fixed wage $\omega^{H} .{ }^{12}$ In addition, they also face a lump-sum tax, $\tau_{t}^{H}$, which is denominated in dollars and which, in real terms, cannot exceed the income earned by the worker. ${ }^{13}$ Thus, the value of these taxes in state $s$, is given by $\rho_{t}(s) \tau_{t}^{H}$. Individuals also have the opportunity to buy and sell state-contingent claims. ${ }^{14}$ Since only oldage consumption is valued, individuals save their entire wage income net of taxes and any state contingent securities in the form of a simple storage technology, which yields $\lambda$ units of consumption in period $t+1$ for every unit of savings at $t$. Thus we can write the skilled worker's problem as

$$
\max _{c_{t+1}^{H}(\alpha), c_{t+1}^{H}(\beta)} \pi U\left(c_{t+1}^{H}(\alpha)\right)+(1-\pi) U\left(c_{t+1}^{H}(\beta)\right)
$$

subject to

$$
\lambda\left[p_{t}^{*}(\alpha) \omega^{H}-p_{t}^{m}(\alpha) \tau_{t}^{H}\right]+\lambda\left[p_{t}^{*}(\beta) \omega^{H}-p_{t}^{m}(\beta) \tau_{t}^{H}\right]=p_{t}^{*}(\alpha) c_{t+1}^{H}(\alpha)+p_{t}^{*}(\beta) c_{t+1}^{H}(\beta)
$$

where $p_{t}^{*}$ is the price of the consumption good and $p_{t}^{m}$ is the price of money. The price of the host-country consumption good is strictly positive while the price of money is nonnegative. It is useful to represent the host-country individual's resources available for consumption after taxes. We define the tax-adjusted endowment, $\bar{\omega}^{H}$, by

$$
p_{t}^{*}(s) \bar{\omega}^{H}=p_{t}^{*}(s) \omega^{H}-p_{t}^{m}(s) \tau_{t}^{H}=p_{t}^{*}(s)\left[\omega^{H}-\frac{p_{t}^{m}(s)}{p_{t}^{*}(s)} \tau_{t}^{H}\right]
$$

where

$$
\frac{p_{t}^{m}(s)}{p_{t}^{*}(s)}=\rho_{t}(s)
$$

\footnotetext{
${ }^{12}$ Alternatively, one can interpret this as an endowment economy where some individuals (high-skilled) receive a large endowment while others (low-skilled) receive a smaller endowment.

${ }^{13}$ Because we are not modelling all uses of tax revenue in the host country, one can interpret the taxes levied as that part of the tax bill which is used to fund government services associated with illegal immigrants.

${ }^{14}$ One can think of individuals as issuing IOU's which are contingent upon whether state $\alpha$ or $\beta$ prevails. We restrict individuals to having an overall non-negative position with respect to the total value of IOU's issued across the two states of nature.
} 
is the goods price of money. The skilled worker's problem can be rewritten as

$$
\max _{c_{t+1}^{H}(\alpha), c_{t+1}^{H}(\beta)} \pi U\left(c_{t+1}^{H}(\alpha)\right)+(1-\pi) U\left(c_{t+1}^{H}(\beta)\right)
$$

subject to

$$
\left[p_{t}^{*}(\alpha) \bar{\omega}^{H}+p_{t}^{*}(\beta) \bar{\omega}^{H}\right] \lambda=p_{t}^{*}(\alpha) c_{t+1}^{H}(\alpha)+p_{t}^{*}(\beta) c_{t+1}^{H}(\beta)
$$

As written, the individual's budget constraint is properly interpreted as workers having unrestricted access to the state-contingent claims markets. ${ }^{15}$

\subsubsection{Unskilled Worker's Problem}

The measure of unskilled host-country workers is $1-\varepsilon$. Unskilled workers inelastically supply their one unit of labor when young. They earn a fixed wage $\omega^{L}$. In addition, they also face a lump-sum tax, $\tau_{t}^{L}$, which is denominated in dollars. Thus, the value of these taxes in state $s$, is given by $\rho_{t}(s) \tau_{t}^{L}$. In all other respects, the unskilled workers problem is derived analogously to the skilled workers and hence is given by

$$
\max _{c_{t+1}^{L}(\alpha), c_{t+1}^{L}(\beta)} \pi U\left(c_{t+1}^{L}(\alpha)\right)+(1-\pi) U\left(c_{t+1}^{L}(\beta)\right)
$$

subject to

$$
\left[p_{t}^{*}(\alpha) \bar{\omega}^{L}+p_{t}^{*}(\beta) \bar{\omega}^{L}\right] \lambda=p_{t}^{*}(\alpha) c_{t+1}^{L}(\alpha)+p_{t}^{*}(\beta) c_{t+1}^{L}(\beta)
$$

\subsubsection{Government Problem}

The host-country government engages in three related activities: collecting taxes, enforcing the border, and providing basic services to illegal immigrants. Taxes are collected from both skilled and unskilled workers from the host countries. ${ }^{16}$ These funds are then used to provide basic services for illegal immigrants and to fund the desired level of border enforcement, denoted by $e_{t}$. We assume that the level of service provided to

\footnotetext{
${ }^{15}$ Bhattacharya et al. (1998), in their appendix, show the equivalence between the above formulation of an individual's budget constraint and ones where these individuals trade on spot markets and other contingent commodity markets and/or contingent money markets.

${ }^{16}$ We are abstracting from modelling all services undertaken by the government. Since our focus is on determinants of illegal immigration we are only modelling those services provide by government which relate to illegal immigration (and similarly for taxes). Finally, government, as referenced in this paper, should be interpreted as all levels (federal, state, and local) of government in the real world.
} 
illegal immigrants, $a$, is constant (on a per person basis) over time but that the quantity of services received in total depends on the fraction of time that immigrants spend getting to and working in the host country, $T(\mu) .{ }^{17}$ In addition we assume that the government runs a balanced budget. Thus the government's budget constraint is given by

$$
\rho_{t}(s)\left[\varepsilon \tau_{t}^{H}+(1-\varepsilon) \tau_{t}^{L}\right]=\gamma T\left(\mu_{t}\right) \rho_{t}(s) a+e_{t}
$$

for $s=\alpha, \beta$, where $\gamma$ represents the fraction of home-country individuals who are migrants. The properties of the transfer-proportion function are described in detail when we discuss the migrant's maximization problem.

\subsection{Home Country}

The home country is characterized by two classes of individuals: migrants and smugglers. Let $\gamma$ be the measure of home-country agents who are employed in the production sector while $1-\gamma$ is the measure of home-country agents who are smugglers. Note that both home-country-born workers and smugglers are restricted from participating in the state-contingent security. ${ }^{18}$ Smugglers work only in the smuggling industry while migrants divide their time between home production, crossing the border, and host-country production. Migrant production in the home country is characterized by a labor only production process. It is assumed that migrants produce a single, perishable final good, which is produced and saved in the migrant's first period of life, and then consumed when old. Finally, all migrant workers are assumed to be unskilled.

\subsubsection{Migrant's Problem}

Each generation of migrants is endowed with one unit of labor when young and nothing when old. Since only old-age consumption is valued, this labor is supplied inelastically when young. ${ }^{19}$ The migrant must decide what fraction of her labor time, $\mu_{t}$, to spend working in the home country and what fraction, $1-\mu_{t}$, to spend

\footnotetext{
${ }^{17}$ The idea is that all illegal immigrants consume some government-provided goods and services. Migrants who are caught crossing the border are provided basic services at detention centers and are returned home at government expense. Migrants who successfully cross the border receive services such as education and emergency health care - even though they are usually not eligible for welfare or most other assistance programs. For simplicity, we assume the government provided goods are perfect substitutes for the consumption good and that they are transformed at a one-for-one rate. Finally, although amount of time crossing the border and working is denoted by $1-\mu$, we have chosen to define $T$ in terms of $\mu$ for expositional efficiency.

${ }^{18}$ One can think of the participation restriction in the following way. In order to participate in the state-contingent market, the agent needs to supply their host-country passport. We have no mechanism for faking passports in this model economy, therefore, the participation restriction is a legal restriction.

${ }^{19}$ The migrant's problem is largely the same as in Guzman et al. (2008).
} 
crossing the border and working in the host country. However, merely deciding to go and work in the host country does not guarantee that the migrant will be successful in her attempt(s) to cross the border. Thus, the fraction of time spent emigrating from the home country, $1-\mu$, is further divided into two activities; time spent actually working in the host country $M(\cdot)$ and time spent crossing the border, $1-M(\cdot){ }^{20}$

The amount of time used in crossing the border depends on the level of border enforcement implemented by the host country, $e_{t}$, and the amount of services, $q_{t}$, a migrant obtains from smugglers. Thus, the amount of time spent working in the host country is a fraction of the time allotment not spent working in the home country; that is, $M\left(q_{t}, e_{t}\right)\left(1-\mu_{t}\right)$, where $0 \leq M\left(q_{t}, e_{t}\right) \leq 1$. Conversely, the time lost crossing the border is given by $\left[1-M\left(q_{t}, e_{t}\right)\right]\left(1-\mu_{t}\right)$. The level of border enforcement, $e_{t}$, is taken as given by the migrant. It is assumed that if $e_{t}=0$, then there is no border enforcement and $M\left(q_{t}, 0\right)=1$ for all $q_{t} \geq 0 .{ }^{21}$ In addition we assume that $0>M_{e}>-\infty$. Thus, an increase in the level of enforcement reduces the amount of time spent working in the host country.

Since crossing the border is time consuming, smugglers exist to reduce the crossing time. At date $t$, migrants can purchase a quantity $q_{t}$ of smuggling services, taking the price, $p_{t}$, as given; where $p_{t}$ is measured in units of the home-country production good. It is assumed that the greater the quantity of smuggling services obtained, the less time is used to cross the border, that is, $M_{q}>0$, and that there are decreasing returns to additional units of smuggling services, $M_{q q}<0$. In addition, it is assumed that $M_{q}<\infty$ and $0<M\left(0, e_{t},\right) \leq 1 .^{22}$

Migrants who work in the home country earn a fixed wage $\omega$ per unit of time spent in home production. ${ }^{23}$ Any income not spent on smuggling services is saved via a simple storage technology in the home country. For every unit of output saved at time $t$, the migrant receives one unit of consumption good at date $t+1$. Migrants who are successful in crossing the border earn a fixed wage $\omega^{* L}$ in the host country and save in the host country via the same storage method as in the home country. ${ }^{24}$ In addition, the migrant receives

\footnotetext{
${ }^{20}$ We define $M$ to lie inside the unit interval.

${ }^{21}$ Open borders correspond to perfect labor mobility.

${ }^{22}$ The latter assumption implies that even without the aid of the smuggler, a migrant will eventually cross the border and spend some time working in the host country.

${ }^{23}$ Alternatively, one can think of $\omega$ as an endowment which the migrant receives continuously throughout his young period life. Thus, if the migrant choose to stay in the home country for $\mu$ fraction of his young life, then she will receive only $\omega \mu$ of the total endowment possible.

${ }^{24}$ It is assumed that migrants are low skilled and thus enter that segment of job market paying lower wages, $\omega^{L}$. We assume that this wage is fixed and thus think of this as a minimum wage earned by all low skilled workers in the host country. Alternatively, one can also think of this as an endowment earned by migrants in the host country which will be dependent on
} 
transfer payments, $a_{t}$, denominated in dollars, from the host country government. The quantity of dollars received is assumed to be proportional to the quantity of time spent crossing the border and working in the host country, captured by $T\left(\mu_{t}\right)$. We assume that $T$ lies in the unit interval (i.e., $\left.T:[0,1] \rightarrow[0,1]\right)$ and possesses the following properties: $T(0) \leq 1, T(1)=0, T^{\prime}\left(\mu_{t}\right)<0, T^{\prime \prime}\left(\mu_{t}\right)<0 .^{25}$ Thus the total, goods value of transfer payments is given by $T\left(\mu_{t}\right) \rho_{t}(s) a_{t}$.

Finally, unlike the workers in the host-country, migrants are born after the realization of the sunspot and are not able to trade on contingent claims market. We additionally assume that migrants spend their retirement in the host country.

We can formally write the migrant's problem as

$$
\max _{\mu_{t}, q_{t}} U\left(c_{t+1}(s)\right)
$$

subject to

$$
c_{t+1}=\omega \mu_{t}-p_{t} q_{t}+\left\{\omega^{L} M\left(q_{t}, e_{t}\right)\left[1-\mu_{t}\right]+T\left(\mu_{t}\right) \rho_{t}(s) a_{t}\right\} \lambda
$$

and

$$
\begin{aligned}
\omega \mu_{t} & \geq p_{t} q_{t} \\
0 & \leq \mu_{t} \leq 1
\end{aligned}
$$

for $s \in\{\alpha, \beta\} .^{26}$ First order conditions yield the set of equations

$$
\begin{gathered}
\omega=\left\{\omega^{L} M\left(q_{t}, e_{t}\right)-T^{\prime}\left(\mu_{t}\right) a_{t} \rho_{t}(s)\right\} \lambda \\
p_{t}=\omega^{L}\left(1-\mu_{t}\right) \lambda M_{q}\left(q_{t}, e_{t}\right) .
\end{gathered}
$$

the fraction of time actually spent in the host country.

${ }^{25}$ Although the time spent crossing the border and working in the host country is given by $1-\mu_{t}$, given that $\mu_{t}$ lies in the unit interval it is immaterial whether we define $T(\cdot)$ as a function of $\mu_{t}$ or $1-\mu_{t}$. In addition, despite the technical nature of these assumptions, the intuition behind them is quite reasonable. If $T(\mu)$ satisfies these conditions, then illegal immigrants obtain most of their transfers (total, goods value of social services) after first arriving in the host-country and then government provided services decline with duration of stay (assimilation).

${ }^{26}$ We require up-front payment for smuggling services, hence the condition $\omega \mu_{t} \geq p_{t} q_{t}$, and rule out the possibility of borrowing against future earnings or indentured servitude as a means of payment. 
Equation (2) indicates the trade-off associated with migrating; the income (wage) earned per unit of time in the home country must equal the income earned per unit of time in the host-country (the sum of the wages in the host country and transfer payments). Equation (3) indicates that the marginal cost of the smuggling service is equal to the marginal income gain from using smuggling services, where the marginal gain in time working in the host-country labor market is measured by the product $M_{q}\left(q_{t}, e_{t}\right)\left(1-\mu_{t}\right)$. We assume that $U\left(c_{t+1}\right)$ satisfies all the standard conditions necessary for an interior solution; namely $U(0)=0$ and $U^{\prime}\left(c_{t+1}\right)>0$.

\subsubsection{Smuggler's Problem}

Smugglers are restricted to producing smuggling services and may not migrate or work in the home-country production sector. When young, smugglers are endowed with one unit of labor that they supply inelastically. As with migrants, smugglers value only old age consumption and are retired when old. Thus they consume the gross return from investing their savings in the same simple storage technology as migrants. Finally, there exists an initial old generation of smugglers who possess smuggling capital $h_{0}$.

A smuggler's unit of labor is divided between two activities when young: accumulating smuggling capital (research and development), $h_{t}$, and selling border crossings. For a smuggler, these operations are ordered sequentially; that is, the young smuggler first accumulates smuggling capital by crossing people, then begins selling services. We think of smuggling capital as the knowledge of methods and means for circumventing host-country border enforcement. The smuggler uses the remaining time endowment to arrange border crossings. We let $d_{t}$ represent the fraction of time which smugglers devote to accumulating smuggling capital and $\left(1-d_{t}\right)$ be the fraction of time devoted to arranging crossings. ${ }^{27}$

When determining the amount of time to devote to accumulating smuggling capital in period $t$, we assume that the quantity of smuggling capital (knowledge) previously acquired by all past generations, $h_{t-1}$, is available to the current generations of smugglers; that is, there is no depreciation of smuggling capital.

\footnotetext{
${ }^{27}$ One can think of the smuggler's first period as divided into two distinct sub-periods. The initial sub-period of his young life is spent as an apprentice to an old smuggler, who has institutional knowledge about crossing and enforcement. In this sub-period, the smuggler undertakes the actual process of crossing migrants over the border. While the apprenticeship provides no income, it provides the required knowledge to make income-generating arrangements for migrant crossings during the second sub-period.

This is not unlike arrangements smugglers typically have made on the U.S.-Mexico border. In practice, apprentice smugglers "run" the migrants across until they have been caught so many times that they risk prosecution if caught again. They then become coordinators and recruiters charged with getting clients for the new generation of runners. For more information on how smugglers operate, see Spener (2002).
} 
We let the function $g\left(d_{t}, h_{t-1}\right)$ represent the process by which time devoted to capital accumulation is transformed into smuggler's capital. Thus we have

$$
h_{t}=g\left(d_{t}, h_{t-1}\right)
$$

where $0 \leq d_{t} \leq 1$. We assume that $g\left(d_{t}, h_{t-1}\right)$ has the following properties: $g_{d}$ and $g_{h}>0$ and $g_{d d}$ and $g_{h h}<0$. Let $g\left(0, h_{t-1}\right)=0$, that is, a smuggler must devote some time to actually smuggling people over the border in order to develop knowledge about effective crossing methods and techniques. Finally, we assume that for $d_{t}>0, g_{h}\left(d_{t}, 0\right)>1$. Thus, taking the time to accumulate smuggler capital pays bigger dividends when there exists little smuggler capital from previous generations.

The smuggler arranges migration services in a perfectly competitive environment. As such, the representative smuggler takes the price of smuggling services, $p_{t}$, as given. In addition, the smuggler also takes as given the level of enforcement, $e_{t}$, in period $t$. Finally, it is only the process of arranging for migrant crossings that generates income. To produce migration services, the smuggler must devote sufficient time to capital accumulation, so that he may overcome the anticipated level of enforcement. Formally, let the quantity of migration services supplied be given by

$$
\begin{aligned}
Q_{t} & =B\left[h_{t}-e_{t}\right]\left(1-d_{t}\right) \text { for } h_{t} \geq e_{t} \\
& =0 \text { otherwise and }
\end{aligned}
$$

where $B>0$ is a constant scale factor, $h_{t}-e_{t}$ is the effectiveness of the smuggling methods relative to enforcement methods, and $1-d_{t}$ is the fraction of time devoted to selling migration services.

We can therefore write the smuggler's maximization problem as

$$
\max _{d_{t}} U\left(c_{t+1}^{c}\right)
$$


subject to the constraints

$$
\begin{aligned}
c_{t+1}^{c} & =p_{t} B\left[h_{t}-e_{t}\right]\left(1-d_{t}\right), \text { and } \\
h_{t} & =g\left(d_{t}, h_{t-1}\right) \\
h_{t} & \geq e_{t},
\end{aligned}
$$

where $c^{c}$ denotes consumption by the smuggler. Given the interior solution guaranteed by the properties of the utility function, the efficiency condition for the smuggler is

$$
p_{t} B\left\{g_{d}\left(d_{t}, h_{t-1}\right)\left(1-d_{t}\right)-\left[g\left(d_{t}, h_{t-1}\right)-e_{t}\right]\right\}=0
$$

Equation (6) describes the smuggler's trade-off. The first term inside the brackets represents the marginal gain from capital accumulation while the second term inside the brackets represents the marginal cost of time allocated to capital accumulation — time not spent arranging migration services.

\section{Existence of Sunspot Equilibria}

Before focusing on existence and general properties of equilibria, it will be useful to establish the existence of sunspot equilibria. Establishing this result requires only examining equilibrium consumption allocations for host-country individuals. This is the result of the fact that skilled and unskilled host-country workers will insure themselves, via trade in contingent-claims markets, prior to the realization of the sunspot and that, migrants, who enter the host country after the state of nature has been revealed, cannot participate in these markets and thus will merely consume the proceeds from their work. Thus, the existence of sunspots (and in particular sunspot equilibria which are not mere randomizations over certainty equilibria) is strictly a matter of examining the equilibrium allocations of host-country workers. ${ }^{28}$ Given this, and the fact that the setup of host-country workers is almost identical to the unrestricted agents in Bhattacharya et al. (1998),

\footnotetext{
${ }^{28}$ We are thus following the structure and methods developed in Bhattacharya et al. (1998) and Keister (1998) to verify the existence of stationary sunspot equilibria. As Bhattacharya et al. (1998) point out, "...equilibrium in this economy reduces to the determination of equilibrium in a smaller economy with no restrictions on market participation but...in which uncertainty is intrinsic."
} 
their results (from section 3.3) are directly applicable to our economy and we omit a formal proof of the existence and characteristics of sunspots. ${ }^{29}$

However, the existence of sunspot equilibria has interesting implications regarding the impact of immigrants (or any new, younger job entrant) on unskilled (older), native workers. Specifically, any detrimental impact to unskilled workers is not the result of immigrants but rather is the result of choices made by unskilled workers in the face of uncertain future tax burdens. Consider the unskilled worker's consumption. When they pay no taxes, it follows immediately that in the absence of a market in which state-contingent securities are traded, this unskilled worker would simply consume her savings. This implies that access to a market trading state-contingent securities results in consumption of the unskilled worker varying with the state of nature. ${ }^{30}$

Most importantly, this variance of consumption (well-being) does not depend on the usual story in which low-skilled workers suffer wage reductions because of the inflow of migrant workers. Here the wages for lowskilled workers are constant. Consequently, the variance stems from the fiat redistribution scheme (taxes and transfers) and the ex ante incentive to participate in the market trading state-contingent securities. In short, unskilled workers "pay" for the (preferred) redistribution scheme even though their explicit tax burden is zero. In our setting, the trade-off between ex ante efficient participation and ex post variance is a by-product of the sunspot, restricted participation, and the monetary redistribution scheme and not the presence of migrant (new) workers.

\section{Migration and Smuggling Equilibria}

The uncertainty over the state of nature, and the resulting existence of sunspot equilibria, also affects the equilibrium levels of migration, smuggling services, and smugglers' allocation of time. Although individuals in the home-country are restricted from participating in contingent claims markets, their decisions regarding allocation of time and the level of smuggler services to acquire, will differ depending on which state of nature,

\footnotetext{
${ }^{29}$ Formal proofs of existence and characteristics is available from the authors upon request.

${ }^{30}$ Bhattacharya et al. (1998) use the term volatility to refer to the range of equilibrium allocations and prices we are referring to as variation in consumption. Formally, $\left[c_{t}^{* L}(\alpha), c_{t}^{* L}(\beta)\right]$ is a proper subset of $\Re^{++}$and has positive measure because $c_{t}^{* L}(\alpha) \neq c_{t}^{* L}(\beta)$. In contrast, $\left[c_{t}^{* L}\left(s_{t}\right)\right]$ is a singleton and therefore is a measure zero set when the low-skilled worker has access to the market for state-contingent securities.
} 
$s$, prevails. We begin by first discussing some properties of enforcement and smuggling in equilibrium. We then describe the equilibrium laws of motion governing the system and state conditions under which multiple equilibria will exists. Finally we end this section by examining the impact of sunspots on the equilibrium values of migration, smuggler services and smugglers' time allocation decision.

\subsection{Enforcement and Smugglers}

It will be useful to first describe the smuggler's decision on how to allocate her time, $d_{t}$, between capital accumulation and arranging border crossings. The choice of $d_{t}$ depends on the level of enforcement, which is given by equation (1), and can be written as

$$
e_{t}=\rho_{t}(s)\left[\varepsilon \tau^{H}+(1-\varepsilon) \tau^{L}-\gamma T\left(\mu_{t}\right) a\right]
$$

for $s=\alpha, \beta$. As with the taxes paid by host-country workers, we assume that the marginal dollar value of transfers received by migrants is time invariant $-a_{t}=a$. Thus, we can rewrite this expression as $e_{t}^{*}=$ $e^{*}\left(\mu_{t}, \tau^{H}, \tau^{L}, a, \rho_{t}(s), \varepsilon, \gamma\right)$. The following lemma states selected properties about the level of enforcement.

Lemma 1 a) $\left.\left.e_{\mu}^{*}>0, b\right) e_{\rho}^{*}>0, c\right) e_{\tau}^{*}>0$, and d) $e_{a}^{*}<0$.

These results follow directly from simply differentiating equation (7) and hence a proof is omitted. The intuition behind these results is straightforward. Parts (a) through (c) state that if transfers decrease (because migrants spend more time in the home-country), the goods value of dollars increase, or taxes increase, ceteris paribus, then there will be greater funds available for enforcement. Part (d) says that an increase in the dollar value of transfers will decrease the funds available for enforcement for a given level of tax revenue.

From equation (6), one obtains

$$
g_{d}\left(d_{t}(s), h_{t-1}\right)\left(1-d_{t}(s)\right)-g\left(d_{t}(s), h_{t-1}\right)=-e_{t} .
$$


Using equation (8) and the implicit function theorem we can solve for the fraction of time smugglers spend acquiring smuggling capital, $d_{t}^{*}=d^{*}\left(\mu_{t}, \tau^{H}, \tau^{L}, a, h_{t-1}, \rho_{t}(s)\right)$. We derive the effect of changes in several variables of interest on the time allotted for research activity in the following lemma.

Lemma 2 a) $\left.d_{\mu}^{*}>0, b\right) d_{\rho}^{*}>0$, c) $\left.d_{\tau}^{*}>0, d\right) d_{a}^{*}<0$ and e) for $g_{h}>g_{d h}$, then $d_{h_{t-1}}^{*}<0$

The results of Lemma 2 follow directly from differentiating equation (8). ${ }^{31}$ The first three results (Parts (a)(c)) are tantamount to increasing enforcement and part (d) is equivalent to decreasing enforcement and thus is the converse of the first three parts. An increase in border enforcement results in the smuggler allocating greater time to research and development in order to overcome the greater level of enforcement. Finally, an increase in the amount of prior smuggler capital (Part (e)) will lead to less research and development since the marginal payoff to additional effort is lower. In effect, with an increase in accumulated knowledge the young smugglers are reaping the rewards from research efforts undertaken by previous generations.

We use the results of Lemma 2 to characterize the effect that changes in enforcement on the equilibrium quantity of smuggling services, $q^{*}$. Using the quantity of smugglers service in equation (5) and combining it with the results from equation $(4,7$, and 8$)$, we obtain

$$
q_{t}^{*}=\frac{(1-\gamma) B}{\gamma}\left\{\left[g\left(d_{t}\right)-e_{t}^{*}\right]\left[1-d_{t}^{*}\right]\right\}
$$

Applying the implicit function theorem yields $q_{t}^{*}=q^{*}\left(\mu_{t}, h_{t-1}, \tau^{H}, \tau^{L}, a, \rho_{t}(s), \varepsilon, \gamma\right)$. The properties of $q^{*}$ with respect to key variables are described in the following lemma.

Lemma 3 a) $q_{\mu}^{*}<0$, b) $q_{\rho}^{*}<0$ c) $q_{\tau}^{*}<0$, d) $q_{a}^{*}>0$, and e) $q_{h_{t-1}}^{*}>0$.

The results of Lemma 3 follow directly from differentiating equation (9) and applying the results of Lemma (2). ${ }^{32}$ The intuition is as follows. For parts (a)-(c), changes in $\mu, \rho$, and $\tau$ lead to greater enforcement, which leads to less smuggling activity, as smugglers devote greater time to learning about these new enforcement levels and thus less time actually arranging for crossings. Thus, these 3 parts of Lemma 3 are capturing the effect that a change in border patrol has on the quantity of smuggling services through the effect on the

\footnotetext{
${ }^{31}$ This result is analogous to Lemma 1 in Guzman et al. (2008).

${ }^{32}$ See Guzman et al. (2008), Lemma 2.
} 
smuggler's time allocation. Part (d) is merely the reverse as greater transfers lead to less enforcement and thus more smuggling activity. For a given level of enforcement, smugglers with a higher level of accumulated knowledge (smuggler's capital) - part (e) - will choose to arrange for a greater number of illegal border crossings.

\subsection{Equilibrium Laws of Motion}

We can now condense the equilibria of this economy down to two equations (laws of motion). We can rewrite equation (9) as

$$
q_{t}^{*}=\frac{(1-\gamma) B}{\gamma}\left\{g\left(d_{t}^{*}, h_{t-1}\right)-e^{*}\right\}\left[1-d_{t}^{*}\right],
$$

where the long list of arguments in $d_{t}^{*}$ and $e_{t}^{*}$ are omitted for ease of exposition. The second equilibrium condition comes from the migrants maximization problem and is given by

$$
\frac{\omega^{*}}{\lambda}=\omega^{* L} M\left[q_{t}^{*}, e_{t}^{*}\right]-T^{\prime}\left(\mu_{t}^{*}\right) \rho_{t}(s) a
$$

The conditions and assumptions necessary to prove existence (and numbers) of steady state equilibria are relegated to an appendix ${ }^{33}$ and we merely state the following proposition.

Proposition 1 If there exists a pair $\left(\mu^{* 2}, q^{* 2}\right)$ such that

i) $0 \leq \mu^{* 2} \leq 1$ and $0 \leq q^{* 2}$ and

ii)

$$
q^{* 2}>\frac{(1-\gamma) B}{\gamma}\left[g\left(d_{t}^{*}\left(\mu^{* 2}\right), h_{t-1}\right)-e^{*}\left(\mu^{* 2}\right)\right]\left[1-d_{t}^{*}\left(\mu^{* 2}\right)\right]
$$

iii) and if both

$$
q_{\min } \leq \frac{(1-\gamma) B}{\gamma}\left[g\left(d_{t}^{*}\left(\mu_{\min }\right), h_{t-1}\right)-e^{*}\left(\mu_{\min }\right)\right]\left[1-d_{t}^{*}\left(\mu_{\min }\right)\right]
$$

and

$$
q_{\max } \leq \frac{(1-\gamma) B}{\gamma}\left[g\left(d_{t}^{*}\left(\mu_{\max }\right), h_{t-1}\right)-e^{*}\left(\mu_{\max }\right)\right]\left[1-d_{t}^{*}\left(\mu_{\max }\right)\right]
$$

\footnotetext{
${ }^{33}$ The details and appendix are available from the authors upon request.
} 
then there exists two equilibria: a high-migration, high-smuggler use equilibrium and a low-migration, lowsmuggler use equilibrium.

Figures 1 and 2 depict the two possible situations in which there exist two equilibria. For the remainder of the paper we focus on these two generic cases with two equilibria. However, the results which follow below also encompass those situations where a unique equilibria exists. Finally, we will use the following short-hand notation when referring to the two possible equilibria: the high level of migration and smuggler service utilization will be referred to as the high-migration equilibria and the low level of migration and quantity of smuggler services will be referred to as the low-migration equilibria.

One important point of note is that there exists volatility in migration independent of the sunspot in this model, as evidenced by Figures 1 and 2 - which depict multiple equilibria within a given state of nature. Because there is no selection mechanism for choosing an equilibrium and because the model is static from the migrants perspective, at any given date $t$, either equilibria is equally likely to prevail and it is possible to switch between the two equilibria regularly - thus generating volatility.

The source of this volatility is the fact that services obtained by migrants from the government are nonlinear (in fact concave) in the quantity of time spent working in the home country. The net result of this is that at low levels of migration, migrants are willing to acquire additional smuggler services because the marginal return to migrating is sufficiently high. However, as migration increases, this results in a decrease in the level of enforcement, as (made clear in equation (7)) enforcement is merely the residual of what is left-over from taxes after paying for migrant services. ${ }^{34}$ Thus increased migration lessens the funds available for, and hence level of, enforcement. At some point, this reduced enforcement will lead to a drop in smuggler services as they are not needed to overcome the waning enforcement level. Thus the marginal return to migrating is equal when there is low migration, high enforcement, as when there exists high-migration resulting in lower levels of enforcement. This existence of multiple equilibria combined with a lack of a coordinating mechanism implies that it is entirely possible to observe switching (in no particularly structured way) between equilibria,

\footnotetext{
${ }^{34} \mathrm{By}$ assuming that the quantity of transfers and border enforcement is equal to taxes, we are essentially assuming that there are limited funds available to illegal immigration related services by the government. In addition, the government prioritizes using these funds for social services (transfers) over the use for border enforcement. The federal budget spent on Immigration, Customs and Border Protection in 2010 was less than $0.46 \%$ of the federal budget. Thus, the idea that border enforcement is not a budgetary priority (modeled as the residual of tax receipts) is not unrealistic. This would also be consistent with border states shouldering a large financial burden for enforcement with limited budgetary resources. Finally, see Epstein and Weiss (2011) for an example of a paper which examines government enforcement trade-offs under the constraint of a fixed budget.
} 
thus generating a volatile path with respect to migration flows.

\subsubsection{Sunspots and Equilibrium Migration}

In addition to the volatility possible as a result of multiple equilibria and no coordinating mechanism, the sunspot nature of the economy adds another layer of potential volatility to the level of illegal immigration. The impact of sunspots on equilibrium values often depends on induced changes in migration flows relative to changes in enforcement. As such, we begin this section by detailing when changes in equilibrium values are definitive or ambiguous and then proceed to explain the sources of any ambiguities. Finally, we examine the extent to which sunspots lead to greater volatility in migration and smuggler services.

Since both equations (10) and (11) depend on $\rho(s)$, the equilibrium levels of migration, $\mu^{*}$, and quantity of smuggler services, $q^{*}$, will depend on which state of nature, $s=\alpha, \beta$, prevails. Without loss of generality, we henceforth assume that $\rho(\alpha)>\rho(\beta)$. To understand the impact that a change in the real value of money will have, we examine the relative positions of equations (10) and (11) as depicted in Figures 1 and 2 for the two states of nature. Differentiating equation (10) with respect to goods price of money, $\rho$, yields $d q^{*} / d p<0$, and thus, equation (10) has the configuration denoted in Figure 3 for the respective states of nature $s=\alpha, \beta$. Similarly, differentiating equation (11) yields

$$
\frac{d q^{*}}{d \rho}=\frac{\frac{T^{\prime} a}{\omega^{* L}}-M_{e} e_{\rho}}{M_{q}}
$$

The impact of an increase in the goods price of money depends on when

$$
T^{\prime} a-\omega^{* L} M_{e} e_{\rho} \gtreqless 0 .
$$

Although equation (12) contains many distinct possibilities, we explore only one here. ${ }^{35}$ Let $(\mu(\alpha), q(\alpha))$ and $(\mu(\beta), q(\beta))$ denote values of $\mu$ and $q$ associated with state $\alpha$ and $\beta$ respectively.

\footnotetext{
${ }^{35}$ The other possible cases (for example equation (12) could shift left or right or could be flatter or steeper) are similar, in terms of the methodology for understanding the impact on equilibria and hence are omitted.
} 
Case 1 Suppose that for every pair $(\mu, q)$ satisfying $0 \leq \mu \leq 1$ and $0 \leq q$ and equation (11) that either

$$
T^{\prime} a-\omega^{* L} M_{e} e_{\rho}>0 \text { for all } \mu
$$

or

$$
T^{\prime} a-\omega^{* L} M_{e} e_{\rho}<0 \text { for all } \mu \text {. }
$$

Figure 3 depicts the two possible situations when either $\frac{d q^{*}}{d \rho}>0$ or $\frac{d q^{*}}{d \rho}<0$. When $\frac{d q^{*}}{d \rho}>0$ prevails, then at the high-migration equilibria, an increase in $\rho(s)$ increases the quantity of migration (lowers $\mu$ ) and the impact on the quantity of smuggler services, $q$, is ambiguous (depending on whether equation (10) or (11) shifts more). At the low-migration equilibria, an increase in $\rho$ decreases both the quantity of migration and smuggler services. When $\frac{d q^{*}}{d \rho}<0$, then an increase in $\rho(s)$ has an ambiguous impact on migration in both equilibria. The quantity of smuggler services decreases in the high-migration equilibria and is ambiguous in the low-migration equilibria.

Remark: Although the impact of changes to the goods price of money are not necessarily clear or consistent across the different possible cases, the intuition as to why the results are sometimes ambiguous and asymmetric with respect to the high- and low-migration equilibria is straightforward. The two key factors driving our results are a) the non-linear (and opposing) nature of both $T(\mu)$ and $M(q, e)$ and b) the fact that enforcement funding equals the residual tax income obtained after paying for migrant services. As equation (7) makes clear, the level of enforcement varies with the level of migration. Thus a change in the goods price of taxes and transfers will have different impacts on enforcement depending on the initial level of migration. In addition, given the non-linear nature of $T(\mu)$, the marginal impact of changes to $\rho(s)$ are likely to be even more pronounced for different initial levels of migration. Thus, the marginal benefit of an increase in transfer payments will depend crucially on the current level of migration. Obviously, this marginal benefit can vary significantly depending on whether the high or low-migration equilibria prevail.

This benefit must be weighed against the costs of an increased goods value of tax revenue - namely greater funds available for enforcement. Greater enforcement increases the time spent crossing the border; thus effectively decreasing the wage income from migrating. Given the non-linear nature of $M(q, e)$, the marginal 
impact of a change in enforcement will differ (potentially significantly) depending on which equilibrium prevailed prior to the change in the goods price of money. Thus, the impact of a change in $\rho(s)$ on the high/low-migration equilibria depends entirely on the relative curvatures of the function $T(\mu)$ and $M(q, e)$.

Most importantly however, when examining Figure 3 it becomes obvious that only in vary rare cases will either the level of migration or the quantity of smuggler services (but neither both) be unchanged when comparing high (low) migration equilibria across the two states of nature. Thus the introduction of sunspots into the model economy will affect the volatility of both migration flows and quantity of smuggler services. $^{36}$ The source of this volatility is described above: namely the marginal trade-off which occurs between additional enforcement and migrant services associate with different goods prices of taxes and transfers. Finally, it is also worth noting that in the case where there exists a unique equilibrium for a given state of nature (i.e., when equations (10) and (11) intersect only once for $0 \leq \mu \leq 1$ and $0 \leq q$ and $s=\alpha$ or $\beta$ ) then volatility arises only as a result of the sunspot and not from a lack of a coordinating mechanism.

\section{Comparative Statics: Taxes}

Although the government in this model simply collects taxes to make transfers and enforce the borders, changes in either the taxes collected or the transfers made has an impact on the equilibria because both indirectly impact the funds available to enforce the border. However, as one would expect the impact of changes in taxes or transfers will largely depend on which equilibrium prevails.

Consider the effect of a change in taxes (on either the skilled or unskilled). Differentiating equation (10) yields the following expression:

$$
\frac{d q^{*}}{d \tau}=e_{\tau} \frac{(1-\gamma)}{\gamma} B\{-(1-d)\}<0
$$

Note that an increase in taxes has qualitatively the same effect as an increase in the commodity price of money. Differentiate equation (11) one obtains

$$
\frac{d q}{d \tau}=\frac{-M_{e} e_{\tau}}{M_{q}}>0
$$

\footnotetext{
${ }^{36}$ In the analytical framework we have, it is not possible to determine the size of this impact on volatility without specifying simple functional forms for many variables and simulating results on a computer.
} 
Figure 4 depicts the impact of an increase in taxes on the equilibria, for a given state of nature. There are qualitative differences depending on which equilibria we study. At low-migration equilibrium, an increase in $\tau$, for example, results in a reduction in smuggling services and a decrease in migration. Conversely, when evaluated at the high-migration equilibrium, an increase in taxes results in an increase in migration while the effect on the quantity of smuggling services is ambiguous.

It is not so unusual for the comparative static responses to differ. We offer some intuition to account for why these differences arise. The common thread between the two equilibria is simple; an increase in taxes, for example, increases the level of border enforcement. Other things being equal, the increase in border patrol induces less migration. We see this mechanism operating in the comparative statics evaluated at the low-migration equilibrium; workers respond to the reduced incentive to migrate, spend more time in the home country, and purchase fewer smuggling services.

The general equilibrium effects are more pronounced in the high-migration equilibrium. In particular, the migrant worker's endogenous response can reduce the level of border enforcement. By increasing the amount of time spent in the host country, migrant workers receive a larger transfer payment. From Part (a) in Lemma (1), border enforcement is inversely related to worker's time spent in host country. Thus, migrant workers have an incentive to increase the level of migration. Indeed, this incentive to increase migration is the dominant force operating in our analysis of the tax effect evaluated at the high-migration equilibrium. Along with the increased incentive to migrate, there is additional incentive to purchase smuggling services. Our results indicate that we cannot infer which of the two countervailing effects dominate. Hence, the total effect on equilibrium quantity of smuggling services is ambiguous when evaluated at the high-migration equilibrium. ${ }^{37}$

\section{Conclusion}

In this paper, we examine a two-country model with one-way migration. The destination country uses an interdiction policy — a border patrol — to inhibit this movement. We interpret such cross-country migration

\footnotetext{
${ }^{37}$ Essentially, Part (c) versus Part (a) in Lemma (3).

Note that the same intuition applies if we consider an increase in marginal rate of nominal transfer payments, $a$. For the sake of saving space, we omit the analysis in the paper. We make this result available upon request.
} 
as illegal immigration. Further, we introduce smuggling services into the model economy to provide a market solution that assists migrant workers in their efforts to circumvent the border patrol.

In general, changes in illegal immigration flows are relate to a number of different factors. For instance, changes in wage differentials are predicted to induce a greater flow of illegal immigrants. From a purely micro perspective, a potential illegal immigrant is unlikely to have any market power and will be a wagetaker in deciding where to work. In general equilibrium, the wage differential and flow of illegal immigrants are simultaneously determined so that focusing just on wage differentials as the cause of illegal immigration begs for answers to another set of questions.

An alternative approach is to propose a set of frictions that affect the equilibrium flow of illegal immigrants. A number of papers propose network externalities as an explanation for illegal immigration flows. Basically, building networks of illegal immigrants living abroad will reduce the cost of crossing a border when governments increase efforts to reduce the flow of illegal immigrants. In addition, networks generate a host of other cost-saving mechanisms that assist the immigrant.

In this paper, we offer an alternative explanation to account for changes in the flow of illegal immigrants. Our model economy shuts down the wage differential and network explanations, not because those explanations do not have merit, but rather, we shut down those features so as to isolate alternative, realistic sources of endogenous volatility. In particular, we identify conditions in which there are multiple equilibria. Accordingly, the absence of any coordinating mechanism means that it is possible for the equilibrium quantity of illegal immigrants to switch back-and-forth between the two equilibria. In addition, we propose extrinsic uncertainty - sunspots - to account for volatility in the flow of illegal immigrants. In our setup, we derive conditions under which the presence of sunspots results in equilibria that are not mere randomizations over the certainty equilibria. The importance of these findings is that endogenous fluctuations can account for volatility in illegal immigration flows in the face of constant wage differentials. Consequently, our results offer an alternative to the network externality hypothesis.

Another advantage to our approach is that we introduce the sunspot as impacting the value of transfer payments (or services) offered to illegal immigrants and the intensity of border enforcement. Thus, unlike the network externality approach, our approach develops a direct link between policy variables and the 
volatility in illegal immigration. Both transfer payments and border patrol are frequently discussed when policy makers debate efforts aimed at deterring illegal immigration. To our knowledge, this is the first paper in which these policy variables play a central role in affecting the fluctuations.

A second key contribution is that in contrast to other theoretical models, we consider a case in which there are two (multiple) equilibria. Because we are essentially dealing with a static decision problem, the two equilibria add another layer of endogenous fluctuations to the layer already associated with the sunspot. In other words, the model economy shows that one source of endogenous fluctuation owes to the existence of the sunspot while another contributing factor is the equilibria - the high-migration or the low-migration on which migrant workers coordinate. We do not address the coordination issue in this paper as it pertains to the equilibrium selection mechanism, but simply point out that an added degree of endogenous volatility could be contributing to volatility observed in the illegal immigration data.

There is much room for further research in this model. One issue that deserves attention is to formulate this model with physical capital so that dynamics could be formally developed and the implications studied. This may provide one avenue to resolving the lack of a coordinating mechanism which is generating some of the volatility in our model. Additionally, allowing the migrants and smugglers to be born prior to the realization of the sunspot, but restricting them from participating in state-contingent markets due to geographical limitations, is likely to have interesting implications. In particular, one could conjecture that both migrants and smugglers would attempt to self-unsure by means of their choice of time spent working at home and time spent accumulation capital respectively. This would likely eliminate volatility in migrant flows and smuggler services and result in volatility resulting only from coordination problems. 


\section{References}

Amuedo-Dorantes, Catalina and Cynthia Bansak (2007), "The Effectiveness of Border Enforcement in Deterring and Postponing Repetitive Illegal Crossings Attempts," Unpublished Manuscript, San Diego State University.

Angelucci, Manuela (2012), "US Border Enforcement and the Net Flow of Mexican Illegal Migration," Economic Development and Cultural Change, 60(2), pp. 311-357.

Azariadas, Costas and Roger Guesnerie (1986), "Sunspots and Cycles," Review of Economic Studies, 53(5), pp. $725-737$.

Balasko, Yves (1983), "Extrinsic Uncertainty Revisted," Journal of Economic Theory, 31, pp. 203-210.

Balasko, Yves and Karl Shell (1986), Lump-Sum Taxes and Transfers: Public Debt in the OverlappingGenerations Model, volume Essays in honor of Kenneth J. Arrow. Volume 2. Equilibrium analysis, New York: Cambridge University Press.

Balasko, Yves and Karl Shell (1993), "Lump-Sum Taxation: The Static Economy," in General Equilibrium Growth and Trade, Volume 2: The Legacy of Lionel McKenzie (Robert Becker, ed.), San Diego: Harcourt Brace, pp. 168-180.

Benhabib, Jess and Nishimura Kazuo (1998), "Indeterminacy and Sunspots with Constant Returns," Journal of Economic Theory, 81(1), pp. 58-96.

Bhattacharya, Joydeep, Mark G. Guzman, and Karl Shell (1998), "Price Level Volatility: A Simple Model of Money Taxes and Sunspots," Journal of Economic Theory, 81, pp. 401-430.

Borger, Scott (2009), "Estimates of the Cyclical Inflow of Undocumented Migrants to the United States," Center for Comparative Immigration Studies, Working Paper 181.

Carrington, William J., Enrica Detragiache, and Tara Vishwanath (1996), "Migration with Endogenous Moving Costs," American Economic Review, 86(4), pp. 909-930.

Cass, David (1992), "Sunspots and Incomplete Financial Markets: The General Case," Economic Theory, 2(3), pp. 341-358.

Cass, David and Karl Shell (1983), "Do Sunspots Matter?" Journal of Political Economy, 91, pp. 193-227.

Epstein, Gil S. and Avi Weiss (2011), "The Why, When, and How of Immigration Amnesties," Journal of Population Economics, 24(1), pp. 285-316.

Farmer, Roger A.E. and Jang-Ting Guo (1994), "Real Business Cycles and the Animal Spirits Hypothesis," Journal of Economic Theory, 63(1), pp. 42-72.

Farmer, Roger E. A. and Michael Woodford (1997), "Self-Fulfilling Prophecies and the Busniess Cycle," Macroeconomic Dynamics, 1(4), pp. 740-769.

Gathmann, Christina (2008), "Effects of Enforcement on Illegal Markets: Evidence from Migrant Smuggling Along the Southwestern Border," Journal of Public Economics, 92(10-11), pp. 1926-1941.

Guzman, Mark G., Joseph H. Haslag, and Pia M. Orrenius (2004), "Accounting for Fluctuations in Social Network Usage and Migration Dynamics," Federal Reserve Bank of Dallas Working Paper No. 2004-02, federal Reserve Bank of Dallas Working Paper No. 2004-02.

Guzman, Mark G., Joseph H. Haslag, and Pia M. Orrenius (2008), "On the Determinants of Optimal Border Enforcement," Economic Theory, 34(2), pp. 261-296.

Hanson, Gordon H. and Craig McIntosh (2010), "The Great Mexican Emigration," The Review of Economics and Statistics, 92(4), pp. 798-810. 
Hanson, Gordon H. and Antonio Spilimbergo (1999), "Illegal Immigration, Border Enforcement, and Relative Wages: Evidence from Apprehensions at the U.S.-Mexico Border," American Economic Review, 89, pp. $1337-1357$.

Hanson, Gordon H. and Antonio Spilimbergo (2001), "Political Economy, Sectoral Shocks, and Border Enforcement," Canadian Journal of Economics, 34(3), pp. 612-638.

Karlson, Stephen H. and Eliakim Katz (2010), Immigration amnesties, 42(18), pp. 2299-2315.

Keister, Todd (1998), "Money Taxes and Efficiency When Sunspots Matter," Journal of Economic Theory, 83, pp. $43-68$.

Machado, Joël (2012), "On the Welfare Impacts of an Immigration Amnesty," Institut de Recherches Economiques et Sociales de l'Universite catholique de Louvain, Discussion Paper 2012-10.

Mandelman, Federico S. and Andrei Zlate (2012), "Immigration, Remittances and Business Cycles," Journal of Monetary Economics, 59(2), pp. 196-213.

Shell, Karl (1977), "Monnaie et Allocation Intertemporelle," Mimeo, Centre National de la Recherche Scientifique.

Spener, David (2002), "Migrant Smuggling as a Transuational Cottage Industry," Mimeo, Trinity University, San Antonio, Texas.

Stark, Oded and You-Qiang Wang (2002), "Migration Dynamics," Economic Letters, 76, pp. 159-164.

Taylor, J. Edward (1986), "Differential Migration, Networks, and Information and Risk," in Research in Human Capital and Development: Migration, Human Capital and Development, volume 4, JAI Press Inc., pp. $147-171$.

Woodford, Michael (1986), "Stationary Sunspot Equilibria in a Finance Constrained Economy," Journal of Economic Theory, 40(1), pp. 128-137.

Woodford, Michael (1987), "Three Questions About Sunspot Equilibria as an Explanation of Economic Fluctuations," American Economic Review, 77(2), pp. 93-98. 


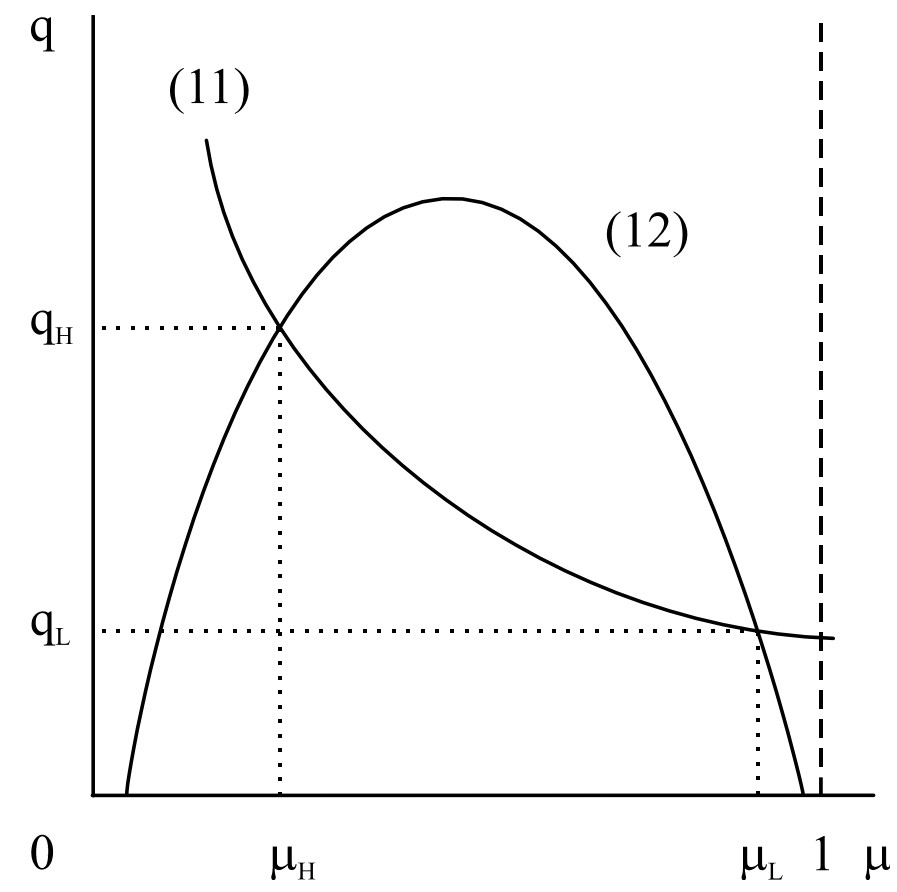

Figure 1: Multiple Equilibria with High and Low Migration Levels

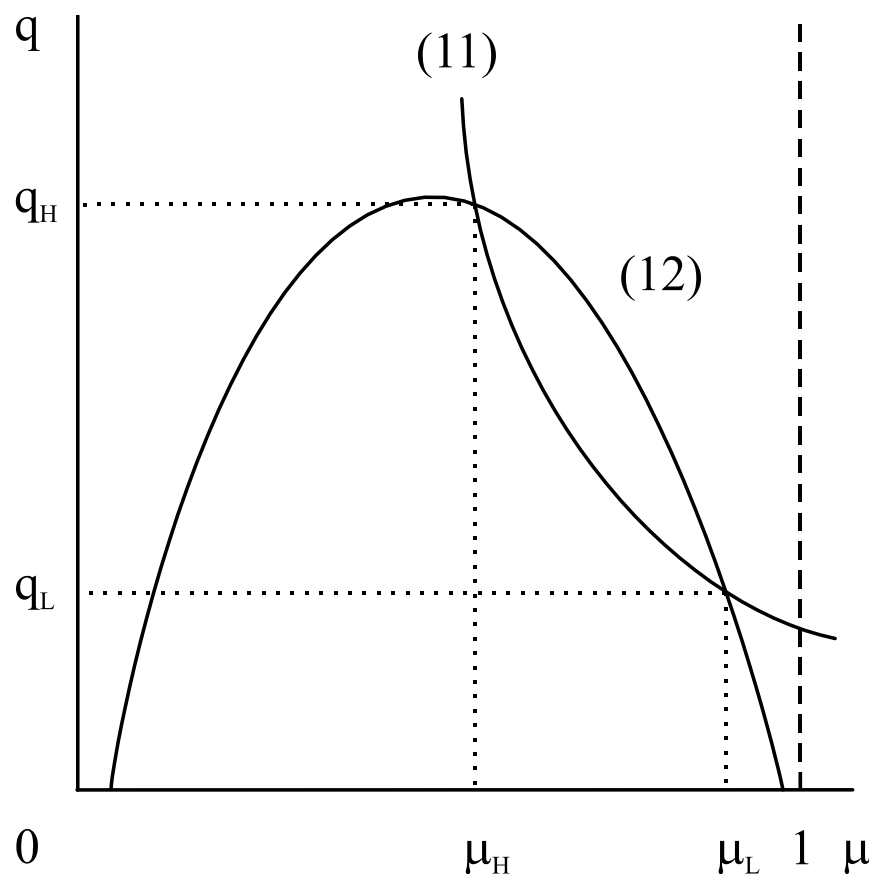

Figure 2: Multiple Equilibria with Low and Lower Migration Levels 


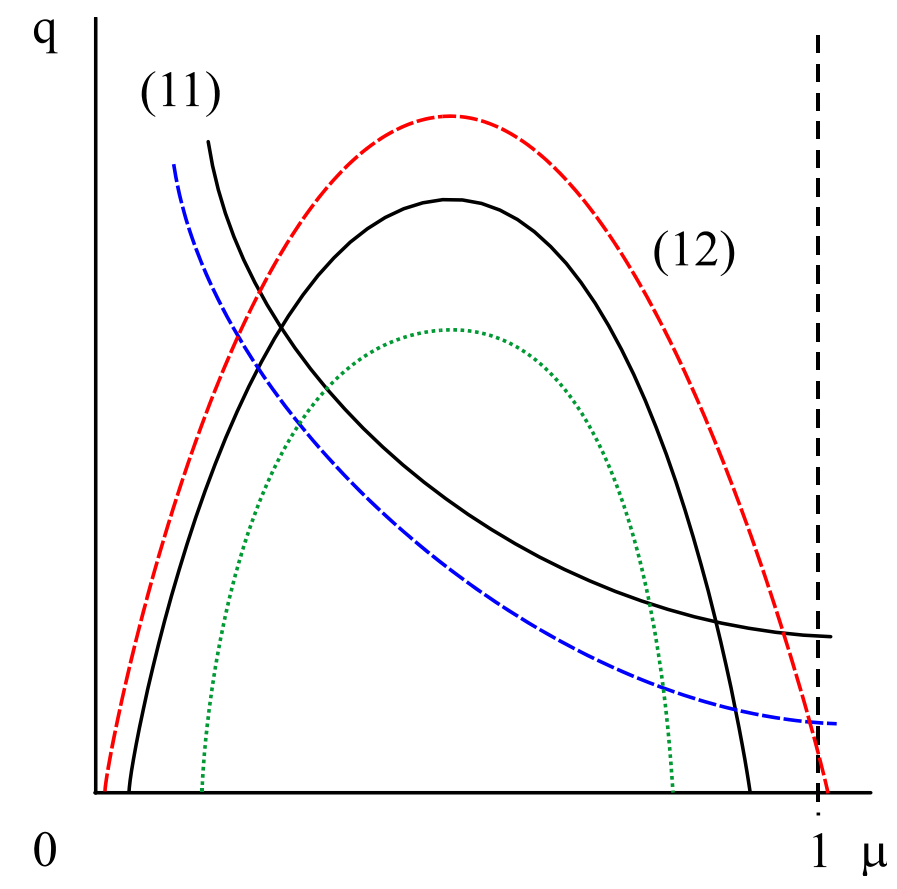

Figure 3: Equation (11) shifts up (down) as a result of an increase in the goods price of money

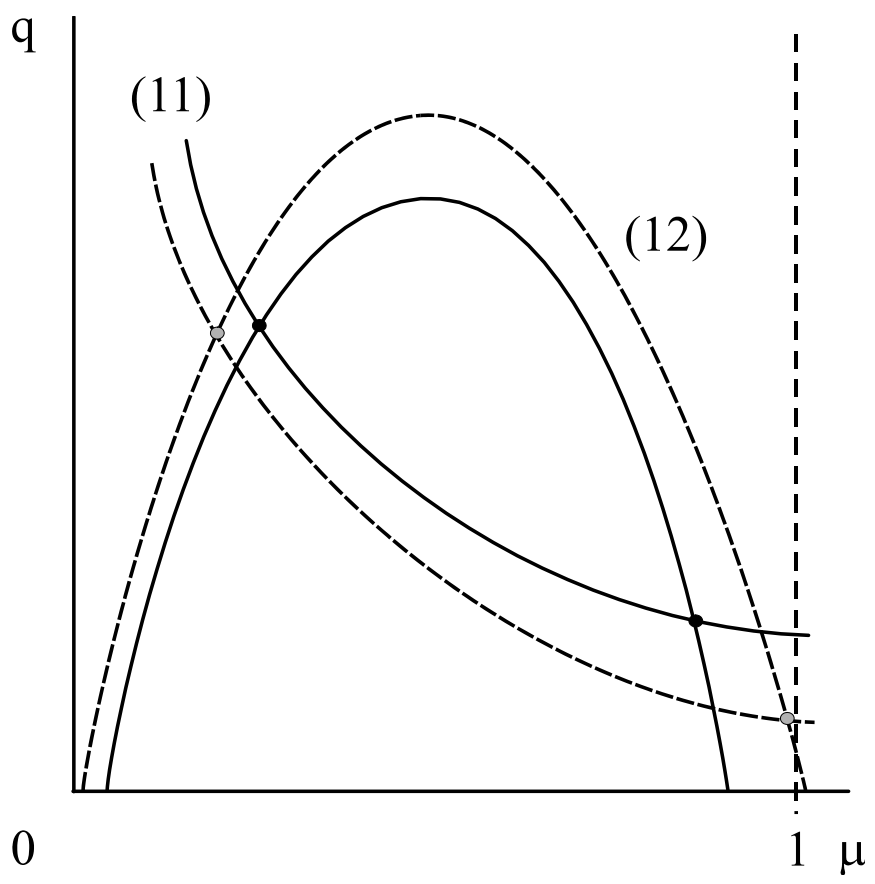

Figure 4: Increase in Taxes Paid 